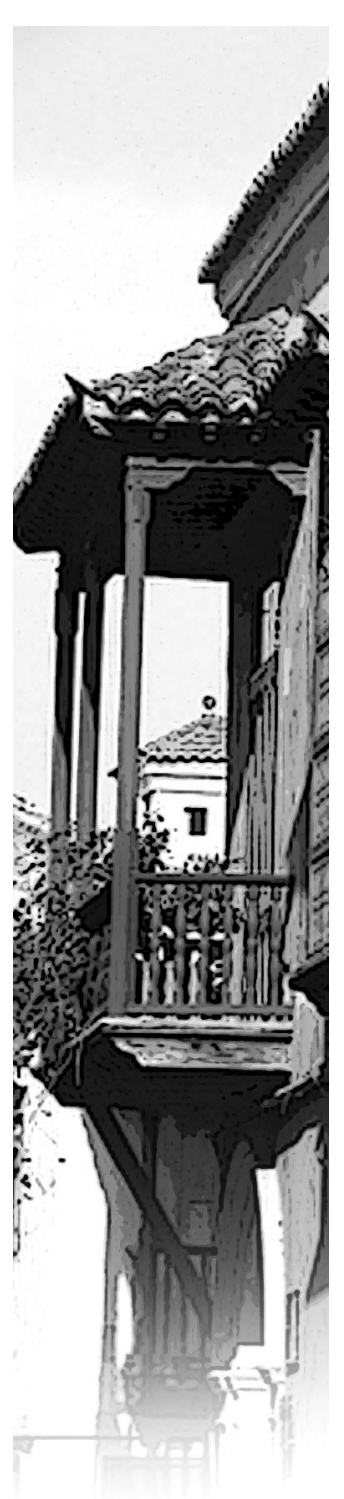

\title{
EXPRESIÓN DE PROTEOGLICANOS EN LA PRÓSTATA: BIOMARCADORES POTENCIALES CON IMPLICACIONES PATOLÓGICAS
}

\section{REYES-RAMOS NIRADIZ}

La investigación en el campo de los proteoglinos está expandiéndose continuamente a medida que se descubren nuevas funciones para los diferentes miembros de este grupo de moléculas bioactivas. De gran interés es el descubrimiento de la ubicación intracelular de algunos proteoglicanos, lo cual ha sido objeto de la investigación reciente.

En el presente libro se describen los experimentos y resultados desarrollados por el Grupo de Investigación Genética y Biología Molecular de la Universidad de Cartagena, los cuales

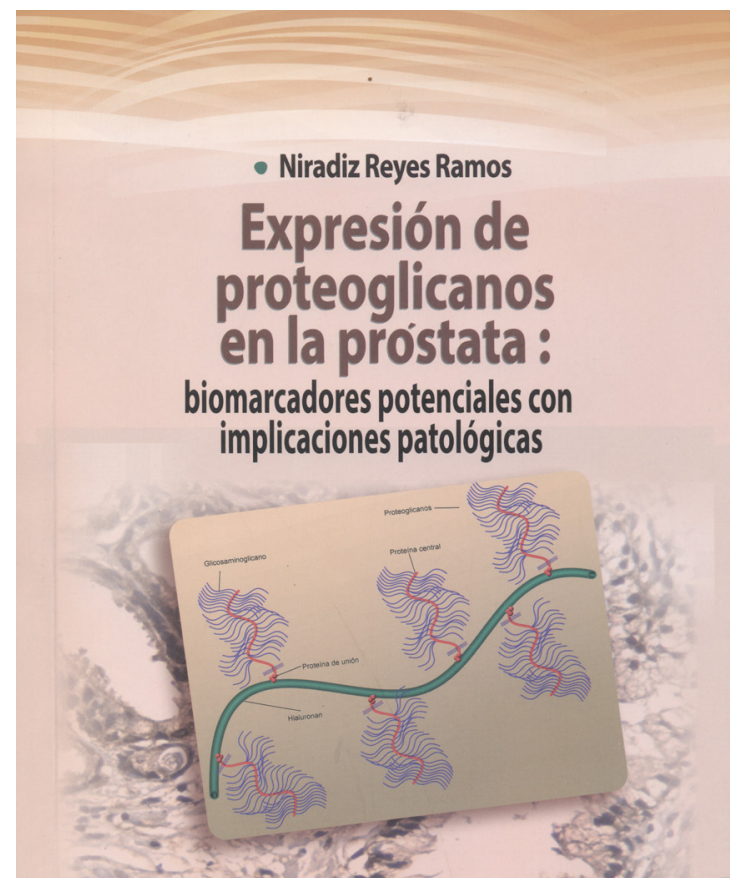
han conducido a identificar la implicación en cáncer de próstata de miembros de este grupo biológico de componentes de matriz extracelular conocidos como proteoglicanos, especialmente los de la familia de pequeños proteoglicanos ricos en leucina.

También se revisa la literatura científica alrededor del cáncer de próstata, la próstata misma, los proteoglicanos y su implicación en el desarrollo y progresión del cáncer, con especial énfasis en el de próstata.

La doctora Niradiz Reyes Ramos es Química Farmacéutica de la Universidad de Cartagena, Magíster y $\mathrm{PhD}$ en Microbiología e Inmunología del New York Medical Collage, Nueva York-EE.UU. Actualmente se desempeña como profesora de la Facultad de Medicina de la Universidad de Cartagena-Colombia y es la directora del Grupo de Investigación Genética y Biología Molecular. 